\title{
The Impact of Information Systems on the Governmental Administration in the Arab Republic of Egypt in Light of the Digital Revolution
}

\author{
Aryan Abdullwahab Qader \\ Department of Information Technology \\ Institute of Graduate Studies and Researches, Alexandria University \\ 163 Horreya Avenue, El Shatby 21526, P.O. Box 832, Alexandria, Egypt \\ arean96@yahoo.com
}

\begin{abstract}
With the emergence of the digital revolution, the world has changed drastically. The impact was great enough to drag the developing world into using information systems in governmental administration; changing the entire course of administration in those developing countries. The information systems are a better substitute for the systems the governments use in order to offer a better service for its citizens. Most of those services that the governmental administrations offer are connected to the internet and can be accessed through it. The developing countries including the Arab world understood the importance of information systems and began to employ them gradually.

The governmental information systems in Arab countries are currently under pressure due to the growth. Those obstacles and challenges occur due to the technical change which showed the effects of information systems in all developing fields. Today, it is impossible to think of developing the social and economic fields without paying a great deal of attention to the information systems.

This research aims to study the effect of using and applying the information systems in the administrations of the Arab countries and the problems and obstacles that occur in using those systems.
\end{abstract}

\section{Introduction}

One of the major problems in the Arab world in general is administration. Especially when it comes to governmental administration, the problems vary due to the lack of resources, poverty and whatnot. However, those are merely reasons for the problem with Egypt. Egypt's main 
problem is with administration regardless of its reasons and that reflects on the problems that it faces.

The physical resources and the human resources are the most important for governmental companies and ministries. However, it wasn't until the rising of the information role was revealed that those companies and ministries realized the importance of information. Information is the core of all modern governmental administrations. Information systems are without a doubt necessarily for communications and monitoring.

With the recent revolution of information systems the world has witnessed, it is of great importance to make use of those systems in the Arab Republic of Egypt. Those resources can form the strategy to overcome the current circumstances which change rapidly. The competition is growing as well, not only locally but on a world wide scale which means that the country must be able to keep up and avoid the routine in order to keep up with the era of technology.

\section{Information Systems as a Pathway to Develop Administrations:}

Information Systems are systems that are made of a set of elements which use information resources. The information systems receive the data of programs, equipment, networks and human resources and process them into information under supervision. The information and the data are stored in storages that keep the data secure.

\section{The Classifications of Data}

In [figure 1], a virtual model of the components of information systems in shown.

Figure 1 [The Components of Information Systems]

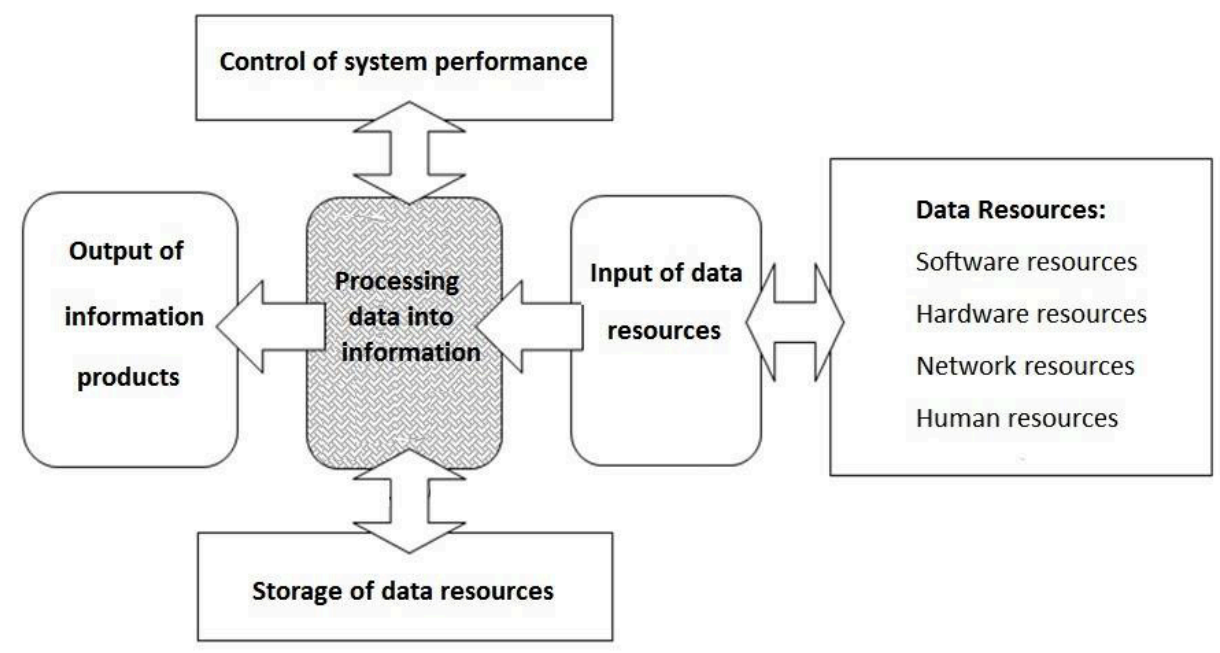

The information plays a major role in keeping the harmony between the rapid changes and the needs and capabilities of the administrative institutions. There are many ways that show the 
need for having an information system. Of those, one of the most important is increasing the specialities, dividing tasks, new decision-making methods and heading to a non-centric administrative system.

\section{Governments and How They See Information:}

Data security has been an issue for a long time which has troubled the governments. However, as a mean for security, different governments had different ideas on how to make the availability of the data most secure. This has led to three different viewpoints on data as shown in [figure 2]. The three extremes represented in [figure 2] vary the levels of barriers that governments put on the data in order to secure it.

Figure 2: Governments Different Viewpoints on Data

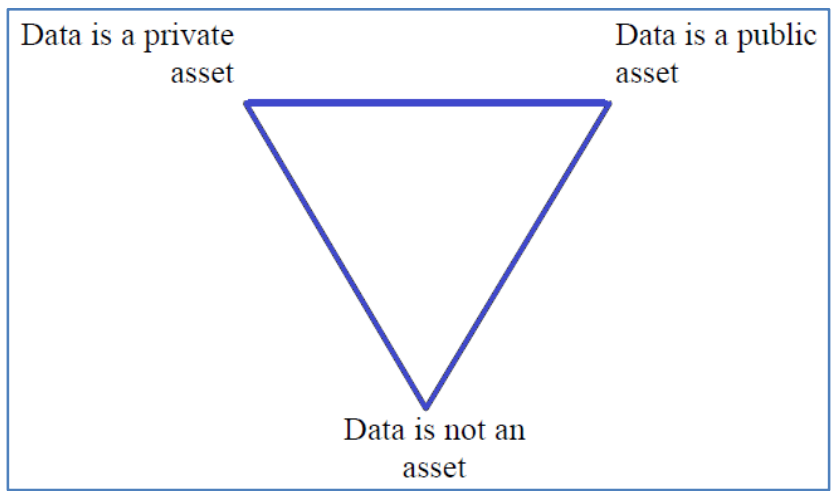

- Data as a public asset: governments identify that the data is public because it has been collected from everyone, thus making it a public property. This point of view can assist both social and economic development. After all, citizens should be given the right and freedom to access the data held about them; however, not without exceptions.

- Data as a private asset: this point of view allows citizens to see the data about themselves and other general kinds of data as long as they pay. The investment of the production of data often has commercial value, thus it should be sold to the highest possible price to earn a valuable revenue for the public sector.

- Data is not an asset: this is where governments don't see data important enough to consider ownership, value or charging. Here, data is a personal asset of specific public sector staff and it is not made available for citizens to access it. [1]

\section{The Private-Public Gap:}

Governments often try very hard to fit the information systems designed for private sectors into the public sectors. Those tries die so often because the public sector often has uncompetitive rates of pay in contrast to the private sectors. Simply put, the high quality IT professionals will not be recruited and the public sector recruitments will lack the experience or the skill. As a result, the e-government projects become underdone in comparison the private sector projects. [2] 


\section{The Importance of Information for Administrative Institutions:}

Typically, information can be perceived in three different types:

- Information as a Resource: as information is used to obtain a certain goal. Information should be used and administrated to achieve the goals of a certain project.

- Information as an Asset: as it can be in the assets the administration owns. For instance, the assets of buildings or machinery which aid the production. That allows the administrative system to have the edge against the competition.

- Information as a Commodity: as information can be considered one of the products of the administration whether to monitor the performance or to aid in the decision making process. [2]

\section{The Value of Information Systems to the Administration:}

The information systems are of crucial importance to the administration of the country. The information system is generally used to operate, collect and transport the information into electronic data. That is known as Information Technology (IT) which includes computers, communication systems, networks, faxes and other means of communication.

The success of the administrative system truly depends on the decision-making technology used by the system. In the United States of America, $50 \%$ of the investor's capital in the administrative system relies on information. In the US, there are approximately 63 computers for each 100 workers and about $88 \%$ of the administrations use computers in their daily work. In 1996, the United States spent over the 500 million dollars on IT.

However, the administrative systems may fall into what is known as the 'social inertia' when it comes to information systems. Typically, 'social inertia' means that no matter how hard you try, nothing gets done. The main causes for social inertia in information systems are:

1. Information takes a small part of organizational decision processes.

2. Organizations prefer to take smaller steps to avoid any damage.

3. Data is a political resource and new information systems may affect particular groups' interests. [2]

Harold Leavitt defined organizations as diamond [figure 3] in which people, technology, structure and tasks are constantly adjusting as they are interrelated. This is an indication of the complexity of the social systems in general. [3] 


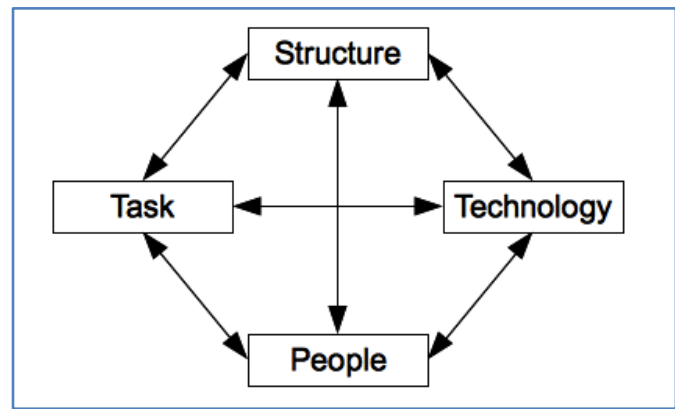

\section{The Different Types of Information Systems:}

Information systems can be divided into four different types within the administration. The main types of information systems are:

- Operation Processing Systems: those systems process the main operations to allow different activities to be available in the administrative system.

- Administrative Information Systems: they consist of groups of operations which permit different levels of administration with the necessary information to aid in processing the operations and decision making.

- Decision Making Systems: the decision making system is considered to be the core of the administrative operation which can be quite troublesome to the administrators in the governmental agencies. The system aids in making the best decision, making up plans and substitutions and choosing the best solutions depending on the available sources.

- Secretary Information Systems: those systems aim to increase the better performance for the secretaries and the official workers in the administrative system.

\section{Aspects of Applying Information Systems in the Administrative Agencies of the Government}

Computers and other means of communications are playing a major role in our daily lives. It isn't known where this technology would stop if it ever would and the evolution it has brought to society is seen best in the developed world. However, there are signs of applying the methods of information systems in the Arab Republic of Egypt:

- Electronic Governments: which applied the technology and use information systems to ease the administrative processes for the citizens in order to obtain the necessary documents, permissions and services.

- The Gap between Information Systems: there is a gap between different places and it varies depending on how the governments respond to the digital revolution. In the developed world, we see that the information systems are improving rapidly as the 
governments work on the necessary infrastructure for the next stage of the digital revolution in what is known as the Information Superhighway.

\section{The Differences in Providing the Informational Services}

There is a great difference between areas that receive informational services and the areas that don't receive the same service in one city. This variety in one city led on to a drastic change in the way organizations think. For instance, IBM decided to shut down entire physical branches and replaced them with branches all across the city as they adopted the experience.

The changes that are expected to happen to information systems [figure 4] especially in Arabian cities and Egypt would have obstacles occurring constantly. Problems and obstacles can divert the course of the usage of information systems.

Figure 4[Impacts, Problems and Obstacles Facing Information Systems]

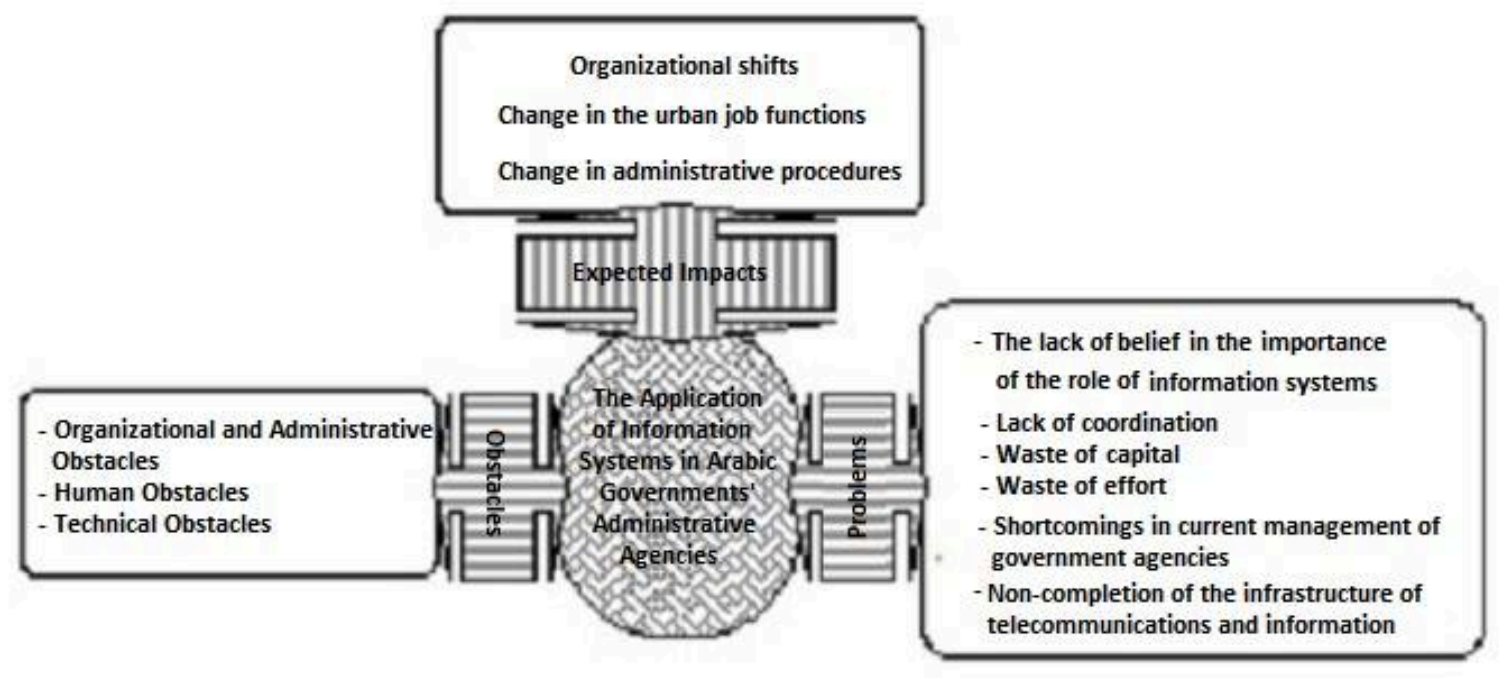

\section{The Quality of Administrative Decisions}

The quality of administrative decisions relies on three major elements: the decision support systems, the management information and the transactions processing systems [figure 7]. The main function of information systems is to provide the citizens with accurate information. Without any of the mentioned elements, the quality of the administrative decisions would fall apart.

\section{Decision Support Systems:}

The Decision Support Systems (DSS) are easily defined. They are a mean to aid in making the decisions for administrative systems. However, the DSS does not replace the decision maker, it 
only does the preparation for the ultimate decision. Those systems also aid in the planning and preparation for the long run in the administration.

Figure 5[The Quality of Administrative Decisions]

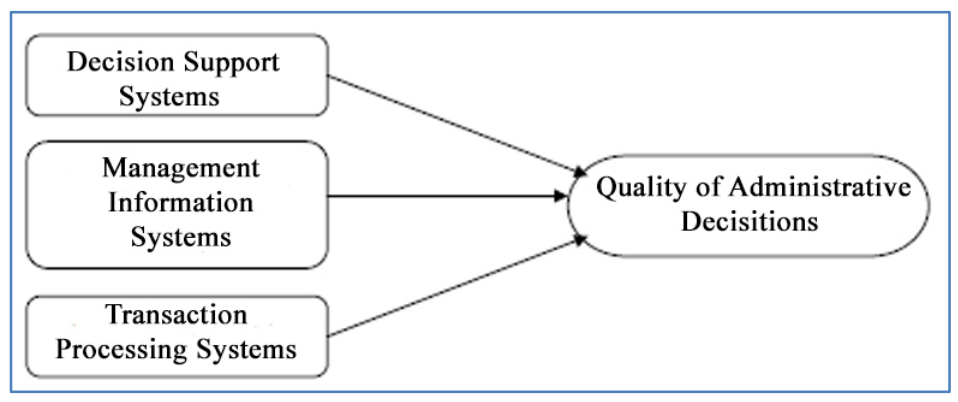

\section{Management Information Systems}

Management Information Systems or otherwise known as Administration Information Systems are systems made up of groups of employees, organizations, operations and sub systems to supply the administration with all the required information.

\section{Transaction Processing Systems:}

Transaction Processing Systems (TPS) are related to the daily operations as they supply the administration with accurate and detailed data. The supply of information happens throughout the day on daily basis, informing the administration of the changes that occur such as the departure or arrival of a certain personnel, the amount of imported or exported goods...etc.

\section{Expectations on the Effects of Information Systems in Egypt}

Drastic changes can occur due to the effects of the information systems on the Arab Republic of Egypt which could possibly change the ordinary routine. Of the major changes that would occur, an organized would address the entire basis of the administration system. That change would decrease the number of levels in the administration and increase the area of monitoring.

Electronic mail would be a great necessity with the changes that would occur as it would be the main method of addressing citizens and employees alike. E-mails would ease the organizing between colleagues who are working on the same or similar tasks. That also means that the routine of having to attend work every day would cease and it means that more concentration would be on the job itself rather than the daily unnecessary tasks that only waste time.

Other changes would be in the form of sharing information through extremely fast methods of delivering information and combining communication tools. That also means that there will be no limited time or place to import or export the information.

Services will be delivered at an increasingly rapid pace whether from the house or office which means that it will be really easy to 0064eliver the tasks before deadlines. Citizens will wait less for responses and the service provided will not take as long to operate or maintain. Bills will be 
paid through the internet or the telephone without a problem and obtaining a passport or a birth certificate will take much less time. Speed will be the trend and complaints would drastically decrease and cease at a point.

While the past decades have witnessed extremely slow reactions from the governmental administrations in the developing countries, that would definitely change with the rapid changes that will happen due to the usage of information systems. In short, information systems will simply make life a lot easier.

\section{The Problems and Obstacles Facing the Administration Systems in the Arab Republic of Egypt}

There are major problems that face Egypt as it progresses and develops. Some of the problems and obstacles can be quite consistent that they slow down the process of using the information systems and others are only habitual problems that can be solved in time.

\subsection{The Belief that the Information Systems Are Unnecessary:}

One of the initial problems that face the information systems in Egypt is the fact that many people will claim that the best place for information systems to be used is the private sector of business. However, even though the private sector in Egypt is more independent and can change the moment the owner or the council of the company desire, the governmental sector also needs information systems to be applied even more than the private sector which already uses them to a certain extent.

\subsection{Lack of Organization:}

Although many developing countries have founded enormous centres for research and collected numerous technicians and specialists, those centres did not face much success because there was no organizing between them to know whether they are working on something unique or not which eventually wasted a lot of money. The lack of strategy and vision not only wastes money on research, but truly doesn't get any of them anywhere.

\subsubsection{User Satisfaction:}

As a part of the success of developing countries, there is also three facilitating constructs that ensure the success: requirement changes, requirements validity and top management support. User satisfaction is directly related to the quality of information, service quality and system quality. The only way to achieve user satisfaction is through those three elements. [6]

In [figure 5] the relationship between user satisfaction and the success of information systems in the developing world is explained. 


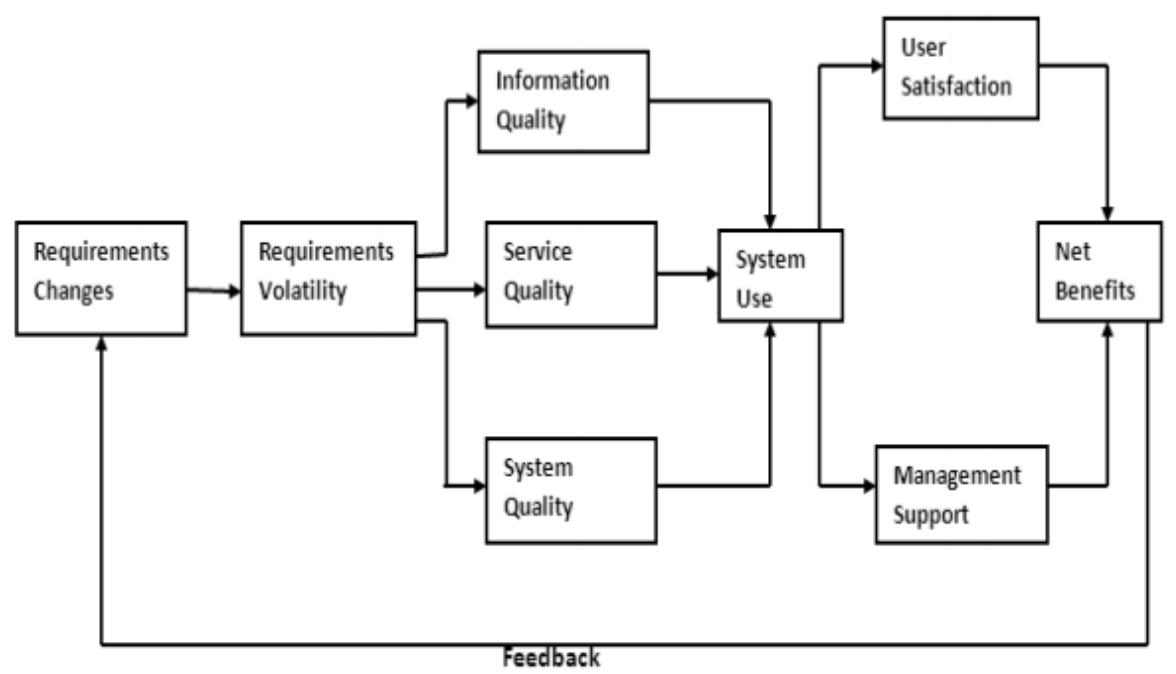

\subsection{The Shortcomings in the Governmental Administrations:}

Because the administrations do not make the best use of their resources and information especially the likes of municipalities which are the core of the city, they have had plenty of shortcomings. The increasing population and the increasing needs of the people demand more yearly which cannot be achieved due to the old methods of the administrations. The governmental administrations do not make the best of the materials they have and thus they are unable to make the best use of the information systems so far.

\subsubsection{Causes of Failure in Applying IT Systems:}

E-governments fail with a percentage of $35 \%$ being a total failure and $50 \%$ being partial failure in the developing countries. This is due to the limited number of resources available in developing countries and therefore cannot afford to spend great amounts of money on the IT projects. The focus of technology in the developing countries is ordering the administration and the citizen and in ensuring of greater accountability and transparency. [5]

However, the motive for applying IT systems in developing countries is highly questionable. The transparency does not require e-government to be achieved and if the motive is such then the IT systems in developing countries are doomed to fail. The gap between the reality of the IT system and the design is often considered a cause of damnation for the IT system as seen in [figure 6]. [6] 
Figure 7 [The Gap between Reality and Design]

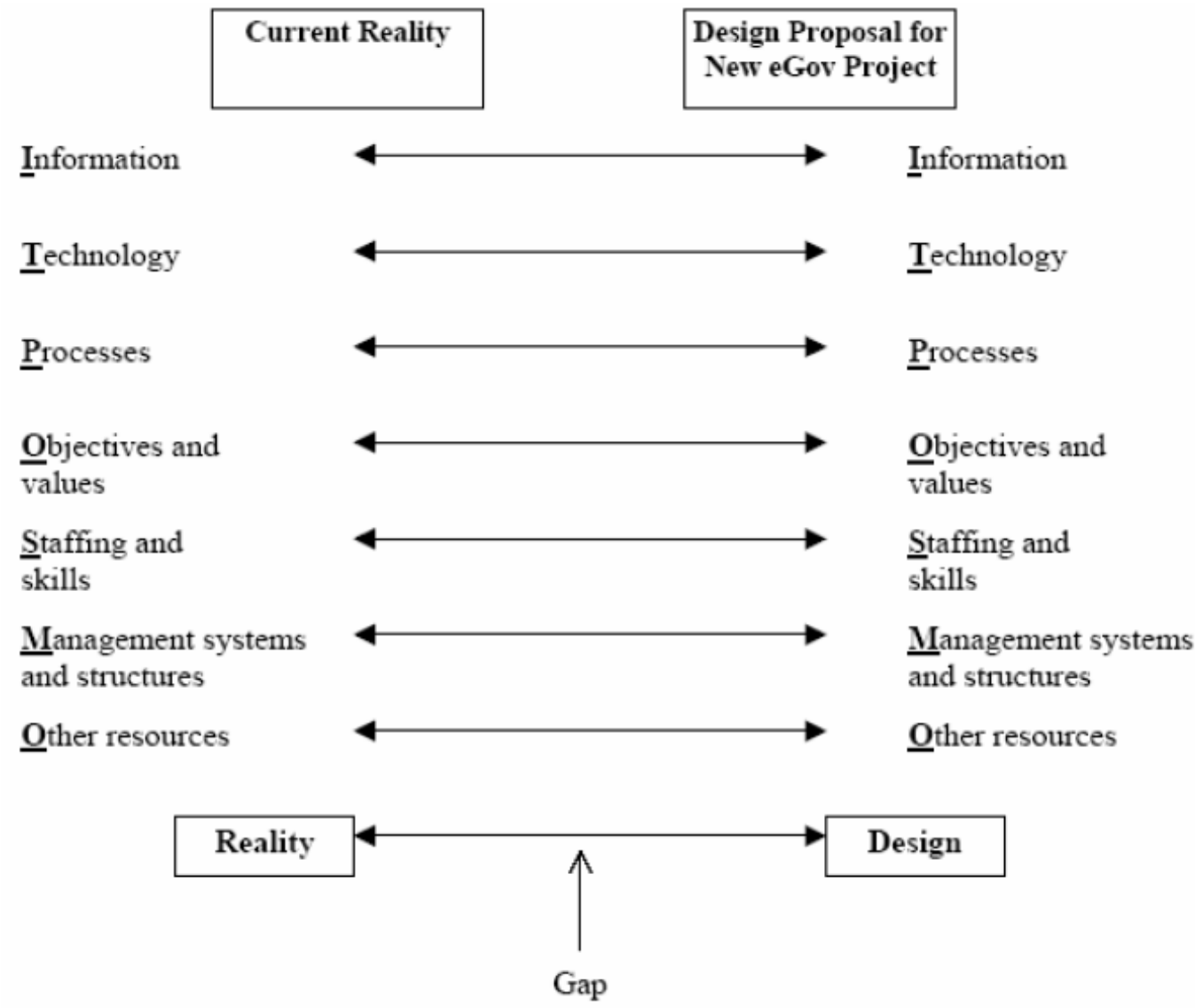

\subsection{The Incomplete Infrastructure:}

The infrastructure of communications is incomplete in most of the Arab world which prevents the Arabs from being able to make the best out of the information systems proposed. Computers and communications are facing a disaster with the incomplete infrastructure which overall is the least in the world. The United Arab Emirates is an exception when it comes to the incomplete infrastructure, however, Egypt is not.

\subsection{Administrational and Technical Obstacles:}

One of the biggest obstacles that stand in the way of using information systems is the lack of a unified policy that can organize, arrange and monitor the usage of information systems across the country. Egypt stands amongst the second class of Arab countries following the likes of Kuwait and Emirates and before the likes of Syria and Morocco in a list of the Arab countries that use information systems. [4]

The reason there is this huge gap between the expected interests which the information systems should bring and the actual interests that have been accessible is due to two main reasons: 
- The lack of a unified policy and the independence of each sector of the administrations all over the country rather than using the same network with the same rules to organize the usage of information systems.

- The information systems have been admitted without making any changes in them to the infrastructure or in the operating methods which means that the information system will be another manual tool that would scarcely decrease the time needed to get the job done.

\subsection{Human Obstacles:}

The human element is the base of every system, yet with over 273 million over 16 and under 60 in the Arab world, most of them do not contribute in the information system. There a number of reasons as to why they do not contribute effectively. [4]

- Illiteracy which was around $39 \%$ of the Arab world in 2002 in contrast to the $22.5 \%$ world-wide.

- The lack of technical specializations in the field which means that there are few programmers who can contribute to information systems and even less technicians who can operate and maintain it.

- The huge gap between the interest of the technicians in the field and the ones who use the information systems.

- The capability of using that technology to threaten the private lives of people and other social elements which could be instantly threatened.

- Using foreign expertise and depending solely on them in some of the Arab countries which means that they will have less interest as they are not a part of the country and their interest will only be temporary.

\section{Conclusion:}

Information can easily be considered one of the most strategic resources in any administrative agency. Without information, those agencies would not be able to access most of their operations without depending on information and they cannot reach the decision making methods without such information. Due to the importance of information to those agencies, they cannot help but consider information systems the cores of the operations they could make and more importantly with the information systems more opportunities could be found and made use of.

Without a doubt, information systems could alter the direction of advancement in the Arab world entirely. Egypt could witness a great rise in its system with the usage of the information systems that could possibly change the direction of how people perform their duties and the slowness would be diminished with the usage of information systems. 
In light of the digital revolution, it is necessary to keep up with the incline of the era. It is most crucial to adjust and overcome the flaws in the system and reshape the entire administrative system that the government uses in order to make it a better place and greater service.

If the Arab countries resist the change and insist on following the outdated systems they use, they will fall under a lesser category. The consequences would be severe especially for countries like Egypt. Doubtless, everything will change gradually with information systems from economics to society and if the Arab world is unable to keep up with the technology, they will be unable to keep up with the rest of the world.

\section{REFERENCES}

[1]. R. Heeks, “Information Systems for Public Sector Management,” Working Paper Series (Paper no. 9), 2000.

[2]. Ciborra, C. \& Navarra, D., "Risks and Challenges of E-Governments in Jordan," in Development Theory, and Aid Policy, Information Technology for Development, 2005.

[3]. Gordon, Judith R. \& Gordon, Steven R.,, Information Systems: A Management Approach., New York: Harcourt Brace College publishers, The Dryden Press, 1999.

[4]. P. G. W. Keen, "Information Systems and Organizational Change," Communications of the ACM, vol. 24, no. 1, 1981.

[5]. H. J. Leavitt, "Applying Organizational Change in Industry: Structural, Technological and Humanistic Approaches," in Handbook of Organizations, Chicago, 1965.

[6]. P. Ssemaluulu, An Instrument to Access Information Systems Success in Developing Countries, Groningen, Netherlands: University of Groningen, 2012.

[7]. D. Dada, "The Failure of E-Government in Developing Countries: A Literature Review," The Electronic Jounral on Information Systems in Developing Countries, London, 2006.

[8]. C. Cibora, "Good Governance, Development Theory, and Aid Policy: Risks and Challenges of E-Government in Jordan," Information Technology for Development, 2005.

[9]. M. J. Shio, "An Approach to Design of National Information Systems for Developing Countries," in Information Systems in the Public Administration, Amesterdam, North-Holland Pub. Co.,, 1983. 